Pacific Journal of Mathematics

SEQUENCES OF QUASI-SUBORDINATE FUNCTIONS 


\title{
SEQUENCES OF QUASI-SUBORDINATE FUNCTIONS
}

\author{
JAMES MiLleR
}

\begin{abstract}
In this paper a theorem is proved which connects bounded analytic functions in the unit disk and sequences of quasisubordinate functions. As an application a necessary and sufficient condition for certain sequences of quasi-subordinate functions to converge is found.
\end{abstract}

Let $f$ and $F$ be analytic functions in $|z|<R$. If there exist two functions $\phi$ and $\omega$ which are analytic in $|z|<R$ and satisfy $\omega(0)=0,|\phi(z)| \leqq 1,|\omega(z)|<R$, and $f(z)=\phi(z) F(w(z))$ for $|z|<R$, then we say that $f$ is quasi-subordinate to $F$ in $|z|<R$ and write $f \prec_{q} F$. Without loss of generality we may assume that $R=1$. This class was introduced by Robertson [2,3].

We note that there are two special cases of quasi-subordination which are of interest: If $\phi$ is the constant function one, then $f$ is subordinate to $F$, and on the other hand, if $\omega$ is the identity function, then $f$ is majorized by $F$.

Let $B$ denote the class of functions $\theta$ which are analytic in $|z|<1$ and satisfy $|\theta(z)| \leqq 1$ for $|z|<1$. Then the functions $\phi$ and $\omega$ which are defined above are elements of $B$. In this paper we prove a theorem which connects functions in $B$ and sequences of quasi-subordinate functions. As an application we find necessary and sufficient conditions for certain sequences of quasi-subordinate functions to converge. This is a generalization of Pommerenke's results [1] on sequences of subordinate functions.

Let $\left\{f_{n}\right\}, n=1,2, \cdots$, be a sequence of functions which are analytic in $|z|<1$ such that $f_{n} \prec_{q} f_{n+1}$ for each $n$ or $f_{n+1} \prec_{q} f_{n}$ for each $n$. When considering the convergence of such sequences we need to require that either the sequence $\left\{f_{n}(0)\right\}$ converges or the functions agree at a single point. In this paper we shall assume that the functions agree at a single point. Further we may assume that the point is $z=0$ for if the functions $f_{n}$ agree at the point $a \neq 0$ then we could consider the functions $g_{n}(z)=f_{n}((z-a) /(1-a z))$. We will use $f_{n}(0)=0$ for all $n$, otherwise the function $\phi$ would be identically one. The proof for the case where $\left\{f_{n}(0)\right\}$ is convergent is similar.

THEOREM 1. Let $\left\{f_{n}\right\}$ be a sequence of functions which are analytic in $|z|<1$ and satisfy $f_{n}(0)=0, \alpha_{n}=f_{n}^{\prime}(0) \neq 0$, and $f_{n}(z) \prec_{q} f_{n+1}$, and let $\phi_{n+1}, \omega_{n+1} \in B$ and $\omega_{n+1}(0)=0$ be such that 


$$
f_{n}(z)=\phi_{n+1}(z) f_{n+1}\left(\omega_{n+1}(z)\right)
$$

for $|z|<1$. If $\sum_{n=2}^{\infty} \arg \phi_{n}(0)$ converges and $\lim _{n \rightarrow \infty} \alpha_{n}=\alpha,|\alpha|<\infty$, then $\prod_{n=2}^{\infty} \phi_{n}(0)$ converges.

Proof. We observe that if $m<n$, then we have $f_{m} \prec_{q} f_{n}$. Thus for $m<n$ there are functions $\phi_{m n}, \omega_{m n} \in B$ where $\omega_{m n}(0)=0$ such that

$$
f_{m}(z)=\phi_{m n}(z) f_{n}\left(\omega_{m n}(z)\right)
$$

for $|z|<1$. Let $\phi_{n n+1}(z)=\phi_{n+1}(z)$. We now observe that

$$
f_{m}^{\prime}(0)=\phi_{m n}(0) \omega_{m n}^{\prime}(0) f_{n}^{\prime}(0)
$$

or

$$
\alpha_{m}=\phi_{m n}(0) \omega_{m n}^{\prime}(0) \alpha_{n} .
$$

Since $0<\left|\alpha_{m}\right| \leqq\left|\alpha_{n}\right|$ for $m<n$ and $\alpha_{n} \rightarrow \alpha$, there exists an integer $K$ such that if $n>m>K$, then

$$
\left|\frac{\alpha_{m}}{\alpha_{n}}-1\right|<\varepsilon
$$

From (1) and (2) we see that

$$
1-\varepsilon<\left|\frac{\alpha_{m}}{\alpha_{n}}\right|=\left|\phi_{m n}(0) \omega_{m n}^{\prime}(0)\right| \leqq\left|\phi_{m n}(0)\right| \leqq 1 .
$$

We now observe that

$$
\phi_{m n}(0)=\prod_{k=m+1}^{n} \phi_{k}(0)
$$

Thus we have

$$
1-\varepsilon<\left|\prod_{k=m+1}^{n} \phi_{k}(0)\right| \leqq 1
$$

for $n>m>K$. Since $\sum_{n=2}^{\infty} \arg \phi_{n}(0)$ converges this says that $\prod_{k=2}^{\infty} \phi_{k}(0)$ converges. Further we have that $\omega_{n}^{\prime}(0) \rightarrow 1$ and $\omega_{m n}^{\prime}(0)=1$.

In applying Theorem 1 to sequences of quasi-subordinate functions we will also need two lemmas for functions in $B$. The proofs of the lemmas are essentially in [1].

LemmA 1. Let $\phi \in B, \phi(0)=0$, and satisfy $|\phi(0)| \geqq \sigma>0$. Then the mapping $w=\phi(z)$ maps the disk 


$$
, z \mid<\rho=\frac{\sigma}{1+\sqrt{1-\sigma^{2}}}
$$

univalently onto a region that contains $|w|<\rho^{2}$.

Lemma 2. For $\varepsilon>0$ and $0<r<1$, there exists an $\eta>0(\eta(\varepsilon, r))$ such that if $\phi \in B$ satisfies $\phi(z)=\sum_{n=0}^{\infty} \beta_{n} z^{n}$ and $\left|\beta_{k}-1\right| \leqq \eta$, then

$$
\left|\phi(z)-z^{k}\right|<\varepsilon, \quad \text { for } \mid z_{1}<r .
$$

THEOREM 2. Let $\left\{f_{n}\right\}$ be a sequence of analytic functions in $|z|<1$ such that $f_{n}(0)=0, f_{n} \prec_{q} f_{n+1}$, and $\alpha_{n}=f_{n}^{\prime}(0) \neq 0$, and let $\phi_{n+1}, \omega_{n+2} \in B$ and $\omega_{n+1}(0)=0$ be such that $f_{n}(z)=\phi_{n+1}(z) f_{n+1}\left(\omega_{n+1}(z)\right)$ for $|z|<1$ and $\sum_{n=2}^{\infty} \arg \phi_{n}(0)$ converges. Then the sequence $\left\{f_{n}\right\}$ converges uniformly in $|z|<r$ for every $0 \leqq r<1$ if and only if

$$
\lim _{n \rightarrow \infty} \alpha_{n}=\alpha, \quad|\alpha|<\infty \text {. }
$$

ProoF. If $\left\{f_{n}\right\}$ converges uniformly in $|z| \leqq r$ for every $0<r<1$ then $\alpha_{n}=f_{n}^{\prime}(0)$ converges. Further since $\left|\alpha_{n}\right| \leqq\left|\alpha_{n+1}\right|, f_{n}(0)=0$, and $\alpha_{n} \neq 0$ we see that $\lim _{n \rightarrow \infty} \alpha_{n}=\alpha \neq 0$ and $|\alpha|<\infty$.

Let $\omega_{n+1}, \phi_{n+1} \in B$, and $\omega_{n+1}(0)=0$ be as defined in Theorem 2 . Further for $m<n$, let $\phi_{m n}, \omega_{m n} \in B$ with $\omega_{m n}(0)=0$ be such that

$$
f_{m}(z)=\phi_{m n}(z) f_{n}\left(\omega_{m n}(z)\right) \text {. }
$$

Suppose that $\alpha_{n} \rightarrow \alpha,|\alpha|<\infty$. Then by Theorem 1 the product $\Pi_{k=2}^{\infty} \phi_{l k}(0)$ converges. We will first show that $\left\{f_{n}\right\}$ is a normal family in $|z|<1$.

Let $r, 0<r<1$, be fixed and $\sigma$ determined by

$$
\sqrt{r}=\frac{\sigma}{1+\sqrt{1-\sigma^{2}}}
$$

Since $\sigma<1$ and $\alpha_{n} \rightarrow \alpha \neq 0$, there exists an integer $N_{1}$ such that

$$
\left|\frac{\alpha_{m}}{\alpha_{n}}\right|>\sigma, \quad \text { for } n>m>N_{1} \text {. }
$$

Further, since $\left|\phi_{m n}(z)\right| \leqq 1$, we have $\left|\phi_{m n}(0)\right|^{-1} \geqq 1$. For $n>m>N_{1}$ we have $\omega_{m n}^{\prime}(0)=\alpha_{m} /\left(\alpha_{n} \phi_{m n}(0)\right)$ or

$$
\left|\omega_{m n}^{\prime}(0)\right|=\left|\frac{1}{\phi_{m n}(0)} \frac{\alpha_{m}}{\alpha_{n}}\right|>\sigma .
$$

Thus by Lemma 1 the mapping $\zeta=\omega_{m n}(z)$ for $n<m<N_{1}$ maps $|z|<\sqrt{r}$ univalently onto a domain that contains $|\zeta|<r$. Let $\psi_{m n}$ be the inverse of $\zeta=\omega_{m n}(z)$ in $|\zeta|<r$, then 


$$
\left|\psi_{m n}(\zeta)\right| \leqq \sqrt{r}
$$

From (3) we may write

$$
f_{n}(\zeta)=\frac{1}{\phi_{m n}\left(\psi_{m n}(\zeta)\right)} f_{m}\left(\psi_{m n}(\zeta)\right), \quad \text { for }|\zeta|<r
$$

For $|\zeta| \leqq r$ we have

$$
\left|f_{n}(\zeta)\right| \leqq \max _{|z| \leqq \sqrt{ } \frac{1}{r}}\left|\frac{f_{m}(z)}{\phi_{m n}(z)}\right| \leqq \frac{1}{\min _{|z| \leqq \sqrt{ } \frac{\sqrt{r}}{r}}\left|\phi_{m n}(z)\right|} \max _{|z| \leqq \sqrt{ } \frac{\sqrt{r}}{r}}\left|f_{m}(z)\right| .
$$

From Lemma 2 with $k=0$, given $\varepsilon>0$, there exists an $\eta$ such that if $\left|\beta_{0}-1\right|<\eta$ then $|\phi(z)-1|<\varepsilon$ for $|z|<r$. Since $\prod_{k=2}^{\infty} \phi_{k}(0)$ converges by Theorem 1 and $\phi_{m n}(0)=\prod_{k=m+1}^{n} \phi_{k}(0)$, there exists an integer $N_{2}$ such that if $n>m>N_{2}$ then $\left|\phi_{m n}(0)-1\right|<\eta$. Let $N=$ $\max \left(N_{1}, N_{2}\right)$. Thus, by Lemma 2 we have that $\left|\phi_{m n}(z)-1\right|<\varepsilon$ for $|z| \leqq r$ and $n>m>N$ or

$$
\min _{|z| \leqq r}\left|\phi_{m n}(z)\right| \geqq 1-\varepsilon .
$$

Hence, for $n>N$ and $|\zeta| \leqq r$ we have

$$
\left|f_{n}(\zeta)\right| \leqq \frac{1}{1-\varepsilon} \max _{|z| \leqq \sqrt{r}}\left|f_{N+1}(z)\right|
$$

Thus there exists $M(r)$ such that

$$
\left|f_{n}(z)\right| \leqq M(r)
$$

for all $n$, that is, $\left\{f_{n}\right\}$ is locally uniformly bounded. Therefore $\left\{f_{n}\right\}$ is normal.

Let $\left\{f_{n_{2}}\right\}$ be a subsequence of $\left\{f_{n}\right\}$ which is uniformly convergent in $|z| \leqq r_{0}$, for every $r_{0}<1$. Let $f$ be the limit function of $\left\{f_{n_{\nu}}\right\}$. Let $\varepsilon>0$ and $r<1$. Then choose $\nu_{0}$ such that

$$
\left|f_{n_{\nu}}(z)-f(z)\right|<\varepsilon / 3
$$

for $\nu \geqq \nu_{0}$ and $|z| \leqq r$. From inequality (5) we have that the sequence $\left\{f_{n}\right\}$ is bounded in $|z| \leqq r$ and thus equicontinuous in $|z| \leqq r$. Therefore there exists a $\delta>0$ such that

$$
\left|f_{n}\left(z_{1}\right)-f_{n}\left(z_{2}\right)\right|<\varepsilon / 3
$$

for $\left|z_{1}-z_{2}\right|<\delta,\left|z_{1}\right| \leqq r+\delta,\left|z_{2}\right| \leqq r+\delta$, and for all $n$.

Using (4), the convergence of $\sum_{n=2}^{\infty} \arg \phi_{n}(0)$, and applying Lemma 2 we have that there exists an integer $M_{1}$ such that if $n \geqq m \geqq M_{1}$, then

$$
\left|\omega_{m n}(z)-z\right|<\delta, \quad \text { for }|z| \leqq r
$$


where $M_{1}$ is chosen so that $\left|\omega_{m n}^{\prime}(0)-1\right|<\eta$ for a suitable $\eta$. Again making use of Lemma 2 we have that there exists an integer $M_{2}$ such that if $n>m>M_{2}$ then

$$
\left|\phi_{m n}(z)-1\right|<\varepsilon / 3 M(r), \text { for }|z|<r .
$$

Let $M=\max \left\{M_{1}, M_{2}, n_{\nu_{0}}\right\}$. If $M \leqq k<n_{\nu}$ and $|z|<r$ then

$$
\begin{aligned}
&\left|f_{k}(z)-f(z)\right| \leqq\left|f_{k}(z)-f_{n_{\nu}}(z)\right|+\left|f_{n_{\nu}}(z)-f(z)\right| \\
&< \varepsilon / 3+\left|f_{n_{\nu}}(z)-\phi_{k n_{\nu}}(z) f_{n_{\nu}}\left(w_{k n_{\nu}}(z)\right)\right| \\
& \leqq \varepsilon / 3+\left|f_{n_{\nu}}(z)-f_{n_{\nu}}\left(\omega_{k n_{\nu}}(z)\right)\right| \\
&+\left|f_{n_{\nu}}\left(\omega_{k n_{\nu}}(z)\right)\left[1-\phi_{k n_{\nu}}(z)\right]\right| \\
&<\varepsilon / 3+\varepsilon / 3+M(r) \varepsilon / 3 M(r)=\varepsilon
\end{aligned}
$$

for $|z| \leqq r$ and $k>M$. This completes the proof of Theorem 2 .

THEOREM 3. Let $\left\{f_{n}\right\}$ be a sequence of functions analytic in $|z|<1$ such that $f_{n}(0)=0, \alpha_{n}=f_{n}^{\prime}(0) \neq 0$, and $f_{n+1} \prec_{q} f_{n}$, and let $\phi_{n+1}, \omega_{n+1} \in B$ and $\omega_{n+1}(0)=0$ be such that

$$
f_{n+1}(z)=\phi_{n+1}(z) f_{n}\left(\omega_{n+1}(z)\right)
$$

for $|z|<1$ and $\sum_{n=2}^{\infty} \arg \phi_{n}(0)$ converges. Then the sequence $\left\{f_{n}\right\}$ converges uniformly in $|z| \leqq r$ for every $r<1$ if the sequence $\left\{\alpha_{n}\right\}$ converges. The limit function is constant if and only if

$$
\lim _{n \rightarrow \infty} \alpha_{n}=0 \text {. }
$$

The proof of this theorem is similar to that of Theorem 2 and Pommerenke's Theorem 2 [1].

\section{REFERENCES}

1. Ch. Pommerenke, On sequences of subordinate functions, Mich. Math. J., 7 (1960), 181-185.

2. M. S. Robertson, Quasi-subordination and coefficient conjectures, Bull. Amer. Math. Soc., 76 (1970), 1-9.

3. - Quasi-subordinate functions, Mathematical Essays Dedicated to A. J. MacIntyre, Ohio University Press, Athens, Ohio, pp. 311-330.

Received May 17, 1971 and in revised form February 7, 1972.

TeXas A AND M UnIVersity 



\section{PACIFIC JOURNAL OF MATHEMATICS}

\section{EDITORS}

\author{
H. SAMELSON \\ Stanford University \\ Stanford, California 94305 \\ C. R. HOBBY \\ University of Washington \\ Seattle, Washington 98105
}

\author{
J. DugundJI \\ Department of Mathematics \\ University of Southern California \\ Los Angeles, California 90007
}

\author{
RICHARD ARENS \\ University of California \\ Los Angeles, California 90024
}

\section{ASSOCIATE EDITORS}
E. F. BECKENBACH
B. H. NeumanN
F. WOLF
K. YoSHIDA

\section{SUPPORTING INSTITUTIONS}

\author{
UNIVERSITY OF BRITISH COLUMBIA \\ CALIFORNIA INSTITUTE OF TECHNOLOGY \\ UNIVERSITY OF CALIFORNIA \\ MONTANA STATE UNIVERSITY \\ UNIVERSITY OF NEVADA \\ NEW MEXICO STATE UNIVERSITY \\ OREGON STATE UNIVERSITY \\ UNIVERSITY OF OREGON \\ OSAKA UNIVERSITY
}

\author{
UNIVERSITY OF SOUTHERN CALIFORNIA \\ STANFORD UNIVERSITY \\ UNIVERSITY OF TOKYO \\ UNIVERSITY OF UTAH \\ WASHINGTON STATE UNIVERSITY \\ UNIVERSITY OF WASHINGTON \\ $* * * *$
$*$
AMERICAN MATHEMATICAL SOCIETY
NAVAL WEAPONS CENTER
}

The Supporting Institutions listed above contribute to the cost of publication of this Journal, but they are not owners or publishers and have no responsibility for its content or policies.

Mathematical papers intended for publication in the Pacific Journal of Mathematics should be in typed form or offset-reproduced, (not dittoed), double spaced with large margins. Underline Greek letters in red, German in green, and script in blue. The first paragraph or two must be capable of being used separately as a synopsis of the entire paper. The editorial "we" must not be used in the synopsis, and items of the bibliography should not be cited there unless absolutely necessary, in which case they must be identified by author and Journal, rather than by item number. Manuscripts, in duplicate if possible, may be sent to any one of the four editors. Please classify according to the scheme of Math. Rev. Index to Vol. 39. All other communications to the editors should be addressed to the managing editor, Richard Arens, University of California, Los Angeles, California, 90024.

50 reprints are provided free for each article; additional copies may be obtained at cost in multiples of 50 .

The Pacific Journal of Mathematics is published monthly. Effective with Volume 16 the price per volume (3 numbers) is $\$ 8.00$; single issues, $\$ 3.00$. Special price for current issues to individual faculty members of supporting institutions and to individual members of the American Mathematical Society: $\$ 4.00$ per volume; single issues $\$ 1.50$. Back numbers are available.

Subscriptions, orders for back numbers, and changes of address should be sent to Pacific Journal of Mathematics, 103 Highland Boulevard, Berkeley, California, 94708.

PUBLISHED BY PACIFIC JOURNAL OF MATHEMATICS, A NON-PROFIT CORPORATION

Printed at Kokusai Bunken Insatsusha (International Academic Printing Co., Ltd.), 270, 3-chome Totsuka-cho, Shinjuku-ku, Tokyo 160, Japan. 


\section{Pacific Journal of Mathematics}

\section{Vol. 43, No. 2 \\ April, 1972}

Arne P. Baartz and Gary Glenn Miller, Souslin's conjecture as a problem on the real line....................................... 277

Joseph Barback, On solutions in the regressive isols ............... 283

Barry H. Dayton, Homotopy and algebraic K-theory ................ 297

William Richard Derrick, Weighted convergence in length ............ 307

M. V. Deshpande and N. E. Joshi, Collectively compact and semi-compact sets of linear operators in topological vector spaces ............. 317

Samuel Ebenstein, Some $H^{p}$ spaces which are uncomplemented in $L^{p} \ldots . .327$

David Fremlin, On the completion of locally solid vector lattices ......... 341

Herbert Paul Halpern, Essential central spectrum and range for elements of

a von Neumann algebra............................... 349

G. D. Johnson, Superadditivity intervals and Boas' test ............. 381

Norman Lloyd Johnson, Derivation in infinite planes . . . . . . . . . . . 387

V. M. Klassen, The disappearing closed set property .............. 403

B. Kuttner and B. N. Sahney, On the absolute matrix summability of Fourier series ........................................... 407

George Maxwell, Algebras of normal matrices................... 421

Kelly Denis McKennon, Multipliers of type $(p, p) \ldots \ldots \ldots \ldots \ldots \ldots . . \ldots 29$

James Miller, Sequences of quasi-subordinate functions ............. 437

Leonhard Miller, The Hasse-Witt-matrix of special projective varieties ..... 443

Michael Cannon Mooney, A theorem on bounded analytic functions ...... 457

M. Ann Piech, Differential equations on abstract Wiener space .......... 465

Robert Piziak, Sesquilinear forms in infinite dimensions ............. 475

Muril Lynn Robertson, The equation $y^{\prime}(t)=F(t, y(g(t))) \ldots \ldots \ldots \ldots .483$

Leland Edward Rogers, Continua in which only semi-aposyndetic

subcontinua separate ............................... 493

Linda Preiss Rothschild, Bi-invariant pseudo-local operators on Lie

groups ...................................... 503

Raymond Earl Smithson and L. E. Ward, The fixed point property for

arcwise connected spaces: a correction ...................... 511

Linda Ruth Sons, Zeros of sums of series with Hadamard gaps .......... 515

Arne Stray, Interpolation sets for uniform algebras............... 525

Alessandro Figà-Talamanca and John Frederick Price, Applications of random Fourier series over compact groups to Fourier multipliers .. 